\title{
Surface treatment of tool steels against galling failure
}

\author{
Pandora Psyllaki ${ }^{1, *}$, Konstantinos Stamatiou ${ }^{1}$, Iason Iliadis $^{1}$, Athanasios Mourlas ${ }^{1}$, \\ Panagiotis Asteris ${ }^{2}$, and Nikolaos Vaxevanidis ${ }^{3}$ \\ ${ }^{1}$ University of West Attica, Mechanical Engineering Department, 12244 Egaleo, Greece \\ ${ }^{2}$ School of Pedagogical \& Technological Education, Department of Civil Engineering Educators, \\ 14121 Heraklion Attica, Greece \\ ${ }^{3}$ School of Pedagogical \& Technological Education, Department of Mechanical Engineering \\ Educators, 14121 Heraklion Attica, Greece
}

\begin{abstract}
In the present study two highly alloyed steel grades, intended for cold working applications, were subjected to plane-contact, nonlubricating sliding friction testing in order to estimate the working regions (applied pressure and sliding velocity) that are governed by mild, moderate and severe wear mechanisms, before and after nitrocarburizing. For this purpose, both tool steel grades were initially pre-subjected to the proper heat treatments, in order to achieve a final bulk hardness of 40, 50 and 60 HRC whereas, after heat treatment, half of the material specimens were further subjected to nitrocarburizing surface treatment. The comparative experimental study of heat-treated and heat-/ surface-treated grades within a wide range of applied pressure and sliding velocity values, in combination to the development of a relevant Artificial Neural Network, allowed to determine the areas of recommended operation of such tribosystems. In all cases, the positive influence of the post-hardening surface treatment was proved; further work is in progress to generalize these preliminary results and establish the relevant wear maps correlating the wear lifetime, the hardening levels and the surface treatment to the operational plane sliding conditions.
\end{abstract}

\section{Introduction}

Galling is one of the most crucial problems that appear when metallic tribosystems, two metallic surfaces in relevant motion to each other, - operate under severe working conditions. An adverse combination of loads, sliding velocities and environmental factors can often induce severe failure of the surfaces in contact, via tearing, ploughing and significant plastic deformation, while massive material transfer between the two surfaces can be simultaneously observed [1, 2, 3, 4]. This disastrous adhesive wear mechanism could result in seizure - virtual welding of the two surfaces - eventually rendering the relevant motion of the two metallic bodies no longer possible. A typical example of such heavily loaded tribosystems in the field of metal working, are the extrusion and shearing

* Corresponding author: psyllaki@puas.gr 
dies, where, in order to overcome the problem of galling, highly alloyed steels are used. These "tool steels", depending on their chemical composition, exhibit high toughness and hardenability, dimensional stability and abrasion resistance.

Various surface modification techniques are employed to protect such Fe-based parts from galling failure, among them thermochemical treatment [5] and pulsed- $\mathrm{CO}_{2}$ laser surface texturing [2]. Previous studies from several groups, among them of one of the present authors [6], have identified nitrocarburizing surface treatment as an effective means for the diminution of the wear coefficient of tool steels by an order of magnitude. Capitalizing on these results, in the present study two representative cold work tool steels after heat treatment and heat/surface treatment were subjected to plane-contact, nonlubricating sliding friction testing. The experimental findings on the friction coefficient evolution and the post-testing evaluation of the wear mechanisms were used to develop a reliable Artificial Neural Network (ANN), dedicated to predict the tribological performance of these materials.

\section{Experimental details}

\subsection{Materials and treatments}

The chemical composition of the two steel grades examined and their characteristic microstructures in their soft-annealed state (22-24 HRC) are presented in Table 1 and Fig. 1 , respectively. Both steels contain carbide-forming elements that render them suitable for cold work applications. Their thorough microstructure characterisation has been reported in previous publications $[3,4]$.

Table 1. Nominal chemical composition (wt. \%) of the materials examined.

\begin{tabular}{|c|c|c|c|c|c|c|c|c|}
\hline & $\mathrm{C}$ & $\mathrm{Si}$ & $\mathrm{Mn}$ & $\mathrm{Cr}$ & $\mathrm{Mo}$ & $\mathrm{V}$ & $\mathrm{Fe}$ & $\mathrm{AISI}$ \\
\hline Steel A & 1.55 & 0.30 & 0.4 & 11.3 & 0.8 & 0.8 & Bal. & $\mathrm{D} 2$ \\
\hline Steel B & 0.6 & 0.35 & 0.8 & 4.5 & 0.5 & 0.2 & Bal. & - \\
\hline
\end{tabular}

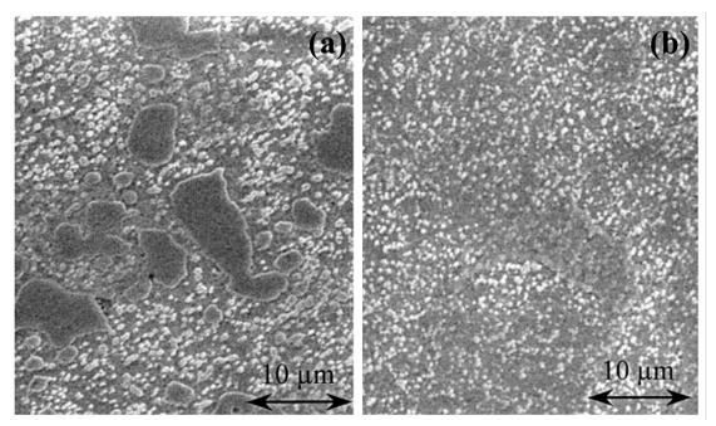

Fig. 1. SEM micrographs of tool steel grades in soft-annealed state: (a) steel A and (b) steel B [3].

Since tool steels are not used in their soft-annealed state, but commonly after their heat treatment to the bulk working hardness required by their specific application, both grades were subjected to heat treatments in order to achieve three series of specimens per grade, having a bulk hardness of 40, 50 and $60 \mathrm{HRC}$. In all cases, the procedure followed was that recommended by the steels' supplier and each thermal cycle included preheating, austenitization and three successive tempering stages; a similar processing is described 
elsewhere [6]. After hardening, half of the specimens of each series were further subjected to liquid nitrocarburizing under conditions similar to those applied on industrial-scale, via the Tufftriding technique that employs specimens' immersion in molten cyanide salt baths at an operating temperature of $580^{\circ} \mathrm{C}$ [5].

Under these conditions, usually, a wear-resistant compound layer with a thickness of $\sim 10$ $\mu \mathrm{m}$ is formed on the steel surface, overlaying a diffusion layer that improves the fatigue behaviour of the material. The thickness of the latter depends on the chemical composition and the hardening level of the steel [4].

\subsection{Tribological testing and evaluation techniques}

A Cameron-Plint pin-on-disk testing machine [2,3], equipped with a force transducer (Fig. 2) was utilized for the real-time recording of the sliding friction coefficient evolution. In particular, a Z-type load cell was used for measuring to total frictional force, in conjunction with an "analog- to-digital (A/D)" converter. The digital signal was recorded with the aid of an in-house developed routine implemented in the LabVIEW ${ }^{\circledR}$ software.

During all tests, two identical cylindrical pins ( $\varnothing 8,55 \mathrm{~mm}$ length) of the tool steel to be examined were mounted and pressed against a rotating disk (counterbody), manufactured of AISI D6 steel and heat-treated to a bulk hardness of $62 \mathrm{HRC}$. All specimens' series were tested by applying a pressure of 3, 5 and 7 bar, -i.e. $0.3,0.5$ and $0.7 \mathrm{MPa}$, respectively,- and a rotational speed of 300 and $1050 \mathrm{rpm}$. All experiments were carried out at ambient atmosphere $\left(25^{\circ} \mathrm{C}, 50 \% \mathrm{RH}\right)$ and lasted for 25000 revolutions, except of the cases where galling occurred, leading to test interruption.
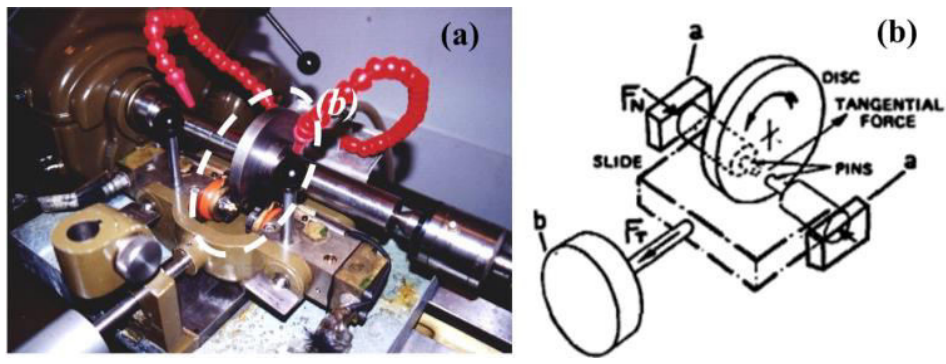

Fig. 2. (a) Cameron-Plint pin-on-disk testing machine [http://triblab.teipir.gr/en/pg000.html] and (b) experimental setup [2].

In order to estimate the level of wear and the mechanisms involved, both the length reduction of the pin and the resulting weight losses were recorded for all the experimental conditions and materials examined, whilst the worn surfaces were post-observed at low magnification via an optical stereoscope.

These experimental findings were used to propose the relevant wear maps, based on the Back-Propagation Neural Network (BPNN) technique, as analysed in paragraph 3.2.

\section{Results and discussion}

\subsection{Tribological testing and evaluation techniques}

Fig. 3 compares the friction coefficient evolution for steel $\mathrm{A}$ in two states, -i.e. after heat treatment to $40 \mathrm{HRC}$ and after being further subjected to a subsequent surface treatment 
(nitrocarburizing),- when applying a pressure of $0.7 \mathrm{MPa}$ at a rotational speed of $300 \mathrm{rpm}$. After a first running-in period, the friction coefficient tends to a rather constant value, indicative of steady-state sliding without galling. The friction coefficient of the heattreated-only material (blue line) varied from 0.24 up to 0.30 , tending practically to a mean value of 0.27 . These fluctuations can be attributed to the presence of large-sized chromium carbides (Fig. 1a) that interfere in the sliding mechanism. The friction coefficient of the nitrocarburized material (red line) exhibited a slightly lower mean value $(0.22-0.24)$, with much lower fluctuations, substantiating the positive influence of the surface treatment. During previous similar experiments on the same steel in its soft-annealed state (24 HRC) [3], galling occurred when applying lower pressure $(0.3 \mathrm{MPa})$ and higher rotational speed $(640 \mathrm{rpm})$, indicating that even heat-only treatment can provide some anti-galling protection.

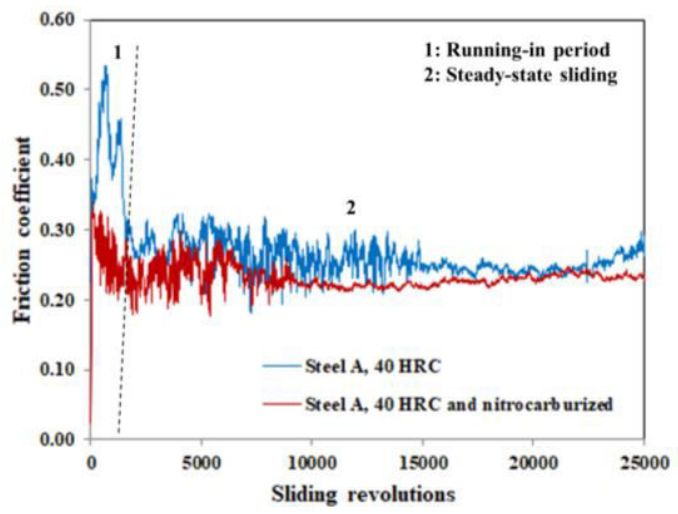

Fig. 3. Friction coefficient evolution of steel A, hardened to $40 \mathrm{HRC}$ with and without subsequent surface treatment (applied pressure: $0.7 \mathrm{MPa}$, rotational speed: $300 \mathrm{rpm}$ ).

For all the experiments carried out with a rotational speed equal to $300 \mathrm{rpm}$ and for both steels, the friction coefficient exhibited likewise a clear steady-state sliding stage until the end of the test, with the mean values of the nitrocarburized material slightly lower than those for the hardened-only state.

In the case of the much higher rotational speed of $1050 \mathrm{rpm}$, after the second stage of steady-state sliding, several of the tribo-pairs arrived to galling [7], depending on their pretreatment and applied pressure. For reasons of brevity, only three characteristic relevant diagrams are presented in Fig. 4; the main remarks extracted from the comparative evaluation of all the experiments can be summarized as follows:

- Galling is more common for steel A when sliding against a rotating disk manufactured of the same steel grade. Even in this case, bulk hardening of the steel to $40 \mathrm{HRC}$ prevented galling when applying low pressure $(0.3 \mathrm{MPa})$. Subsequent nitrocarburizing of the $40 \mathrm{HRC}$-hardened steel prevented galling when applying medium pressure $(0.5$ $\mathrm{MPa}$, Fig. 4a), whilst neither hardening to $40 \mathrm{HRC}$ nor subsequent surface treatment prevented galling at higher pressure $(0.7 \mathrm{MPa})$. In the case of steel A heat-treated to the higher hardness (60 HRC), galling occurred only for the non-surface-treated material (Fig. 4b).

- In the case of steel B that has different chemical composition from that of the rotating counterbody, galling was observed only in the case of the highest pressure applied $(0.7$ $\mathrm{MPa}$ ) on the non-surface-treated material. 

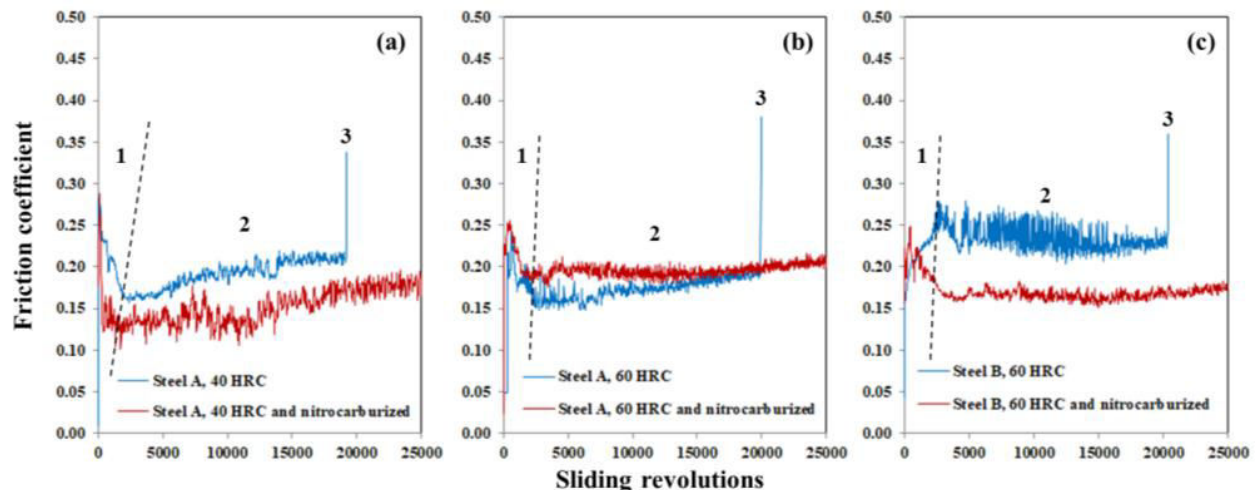

1: Running-in period, 2: Steady-state sliding, 3: Galling

Fig. 4. Friction coefficient evolution at $1050 \mathrm{rpm}$, leading to galling: (a) steel A hardened to $40 \mathrm{HRC}$, sliding against steel $\mathrm{A}$, under $0.5 \mathrm{MPa}$, (b) steel A hardened to $60 \mathrm{HRC}$, sliding against steel A, under $0.7 \mathrm{MPa}$ and (c) steel B hardened to $60 \mathrm{HRC}$, sliding against steel $\mathrm{A}$, under $0.7 \mathrm{MPa}$.

Stereoscopic observations of the worn surfaces allowed distinguishing four different types of material degradation during plane-contact sliding, even in the cases where galling was not taking place (Fig. 5):

- Uniform and progressive material removal (Fig. 5a), under low applied pressure and low rotational speed.

- Progressive material removal accompanied by local oxidation (Fig. 5b), under low applied pressure and high rotational speed.

- Plastic flow of the material at the vicinity of the contact (Fig. 5c), more intense in the cases of lower hardening levels and medium applied pressure.

- Severe plastic deformation (Fig. 5d), increasing with: increasing applied pressure and rotational speed, and decreasing hardening level of the examined steels.
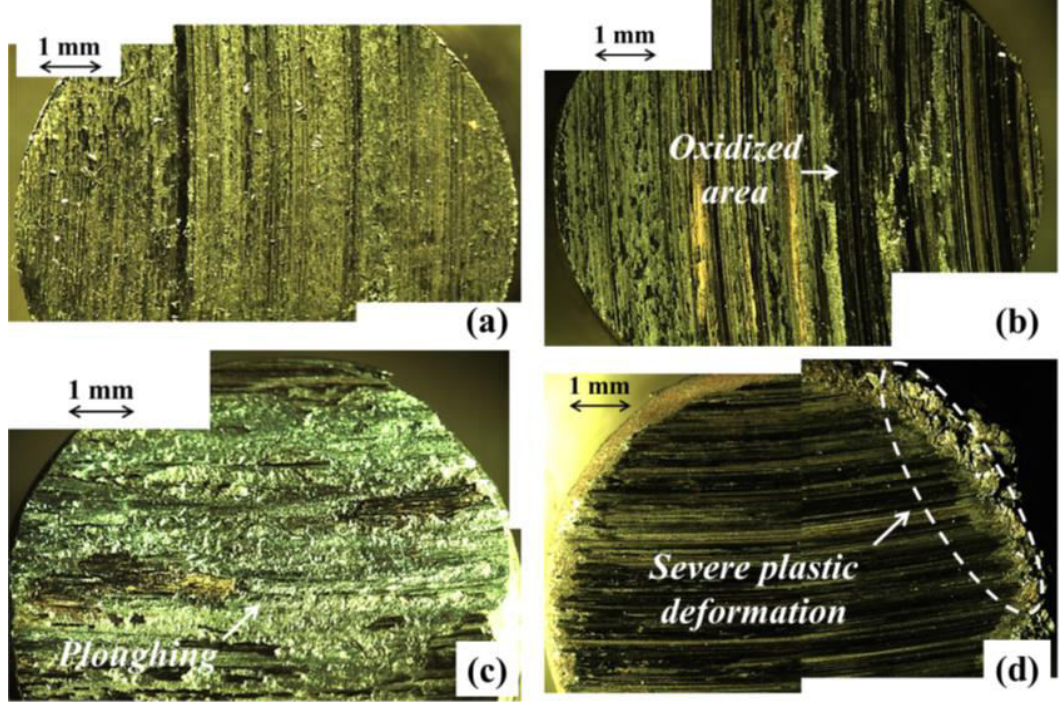

Fig. 5. Different types of material degradation during sliding: (a) uniform material removal, (b) progressive material removal and local oxidation, (c) plastic flow at the vicinity of contact and (d) severe plastic deformation. 


\subsection{Wear maps using Artificial Neural Networks}

This section summarizes the basic concepts of artificial neural networks (ANNs) as well as the architecture of the optimum ANN model developed for the wear characterization of the two steel grades under investigation. ANNs are information processing models configured for a specific application through a training process. A trained ANN has learned to rapidly map a given input into the desired output quantities (similar to curve fitting procedures) and thereby can be used as a meta-model enhancing the computational efficiency of a numerical analysis process. This major advantage of a trained ANN over conventional numerical analysis procedures like regression analysis, under the condition that the training and validation data cover the entire range of input parameters values, is that the results can be produced with much less computational effort [8-15].

In the present study, using the experimental results (72 datasets) concerning the tribological tests of the two highly alloyed steel grades presented in the previous sections, the BackPropagation Neural Network (BPNN) technique was used for the development of a reliable and robust ANN that can predict the wear for these materials. This work focuses on the development of an optimum ANN model able to produce a set of wear maps emphasizing the determination of areas under steady-state wear that are recommended for use. To this end, each input training vector is of dimension $1 \times 7$ comprising the two parameters for the encoding of the material, the two parameters encoding the nitrocarburizing of the materials, the rotational speed, the applied pressure and the bulk hardness. The corresponding output training vectors are of dimension $1 \mathrm{x} 1$ and are based on the type of wear (steady-state wear or not recommended use).

In the light of the above, 36900 BPNN models (900 with one hidden layer and 3600 with two hidden layers) have been studied. Each one of these models was trained by means of 36 datasets (out of the total of 72 , that is a percentage of $50 \%$ ) and the reliability of the results was validated by means of 18 datasets $(25 \%)$ and was tested against the remaining 18 data sets ( $25 \%$ of total), by calculating the Pearson's correlation coefficient $\mathrm{R}$ as well as the Root Mean Square Error (RMSE). The parameters used for the training of NN models are summarized in Table 2.

Table 2. Training Parameters of BPNN models.

\begin{tabular}{|l|l|}
\hline Parameter & Value \\
\hline Training Algorithm & Levenberg-Marquardt Algorithm \\
\hline Number of Neurons per Hidden Layer & 1 to 30 by step 1 \\
\hline Cost Function & Mean Square Error (MSE); Sum Square Error (SSE) \\
\hline Transfer Functions & $\begin{array}{l}\text { Hyperbolic Tangent Sigmoid transfer function (tansig); } \\
\text { Log-sigmoid transfer function (logsig); Linear transfer } \\
\text { function (purelin) }\end{array}$ \\
\hline
\end{tabular}

Based on these results, the optimum BPNN model is that of 7-8-17-1 structure. This network corresponds to the case of architecture with two hidden layers of 8 and 17 neurons respectively. Furthermore, the achieved optimum BPNN corresponds to the case of using as transfer functions the MATLAB function tansig for the first hidden layer, the logsig for the second hidden layer and the purelin for the output layer. Using this optimum ANN model, preliminary wear maps for the two steel materials have been produced. Some representative ones are shown in Figs 6-8. 


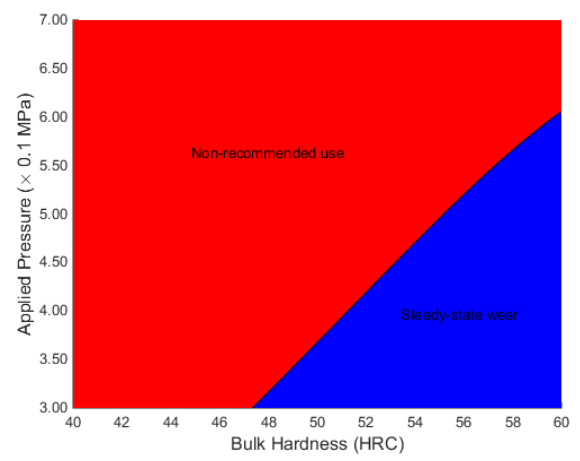

(a)

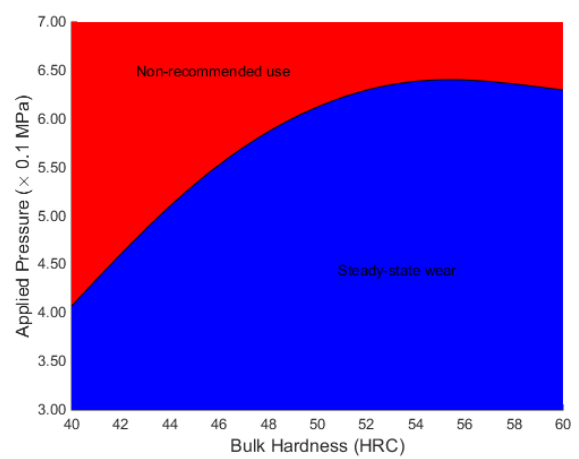

(b)

Fig. 6. Wear maps for steels before nitrocarburizing and under rotational speed $300 \mathrm{rpm}$ : (a) steel A and (b) steel B. Blue area: desirable steady-state wear. Red area: non-recommended combination of bulk hardness (material's property) and applied pressure (operating condition).

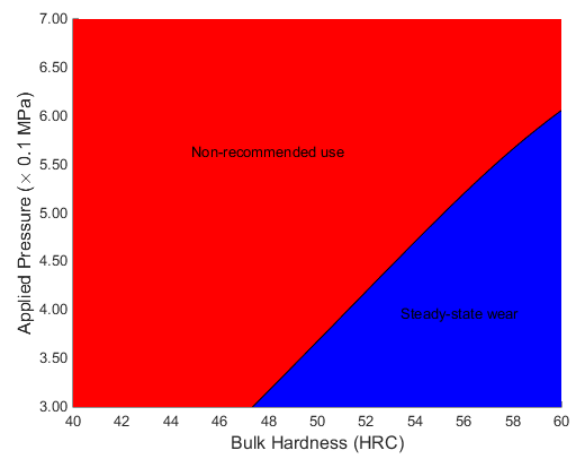

(a)

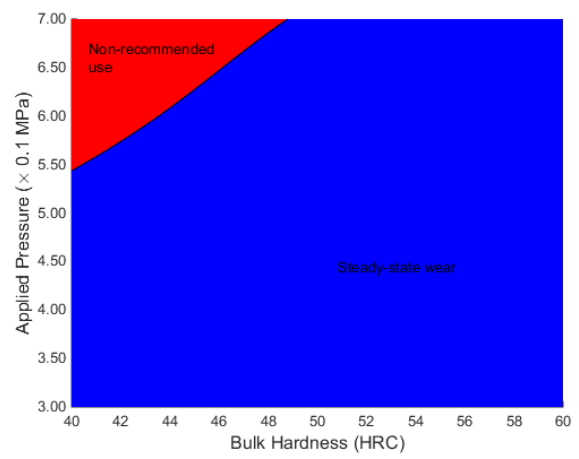

(b)

Fig. 7. Wear maps for steel A under rotational speed 300 rpm: (a) before nitrocarburizing and (b) after nitrocarburizing. Blue area: desirable steady-state wear. Red area: non-recommended combination of bulk hardness (material's property) and applied pressure (operating condition).

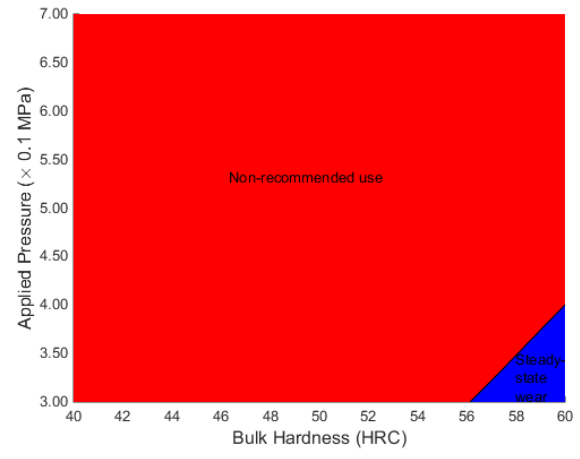

(a)

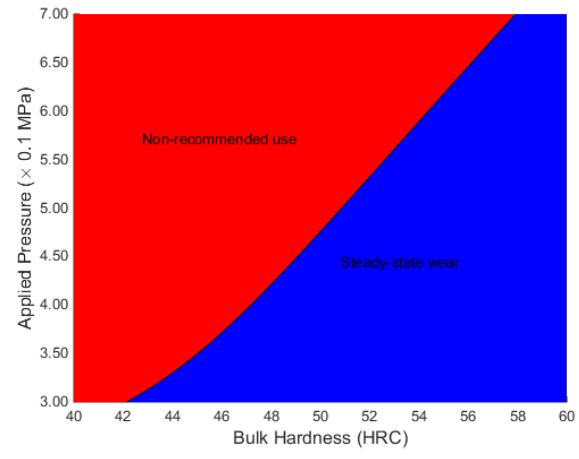

(b)

Fig. 8. Wear maps for steel A under rotational speed $1050 \mathrm{rpm}$ : (a) before nitrocarburizing and (b) after nitrocarburizing. Blue area: desirable steady-state wear. Red area: non-recommended combination of bulk hardness (material's property) and applied pressure (operating condition). 


\section{Conclusions}

Two different highly alloyed steel grades with different hardening levels were surfacetreated via the Tufftriding technique and, consequently, subjected to plane-contact sliding under non-lubrication conditions. The evolution of friction coefficient during testing, together with post-testing optical observations were evaluated, in order to estimate the operational values' range of applied pressure and rotational speed that ensure steady-state wear of the tribosystems examined, without galling or plastic deformation. The experimental findings were used to develop an ANN and to propose the relevant wear maps. The main results can be summarized as follows:

- The choice of different conjugate steel grades is recommended for more severe operational parameters.

- Higher bulk hardness values extend the steady-state wear region, whilst further surface treatment of the hardened steels limits even more the region of non-recommended use.

- Increasing the sliding speed causes displacement of the region of recommended use to higher bulk hardness values.

This approach is currently explored further, employing additional steel grades and operational conditions, in order to propose a generic approach for the construction of more elaborate wear maps that will take into account the specific steels microstructure.

\section{References}

1. J.A. Collins, Failure of materials in mechanical design: analysis, prediction, prevention. John Wiley \& Sons (2nd Edition), New York (1993)

2. D.I. Pantelis, G. Pantazopoulos, S.S. Antoniou, Wear 205, 178 (1997)

3. P. Psyllaki, G. Kefalonikas, G. Pantazopoulos, S. Antoniou, J. Sideris, Surf. Coat. Techn. 16267 (2003)

4. G. Pantazopoulos, P. Psyllaki, Tribology in Industry 37299 (2015)

5. G. Pantazopoulos, Tufftriding and Tennifer Surface Treatment in: Q.J. Wang, Y.W. Chung (eds) Encyclopedia of Tribology. Springer, Boston, 2013

6. C.-M. Karamboiki, A. Mourlas, P. Psyllaki, J. Sideris, Wear 303560 (2013)

7. J.A. Williams, Engineering Tribology. Oxford University Press Inc, New York (1994)

8. P.G. Asteris, S. Nozhati, M. Nikoo, L. Cavaleri, M. Nikoo, Mech. Adv. Mater. Struc. (to be published, DOI: 10.1080/15376494.2018.1430874)

9. P.G. Asteris, K.G. Kolovos, M.G. Douvika, K. Roinos, Eur. J. Environ. Civ. En. 20 s102 (2016)

10. P.G. Asteris, K.G. Kolovos, Neural. Comput. Appl. (accepted, DOI: 10.1007/s00521017-3007-7)

11. P.G. Asteris, P.C. Roussis, M.G. Douvika, Sensors-Basel 17 Art. No 1344 (2017).

12. L. Cavaleri, G.E. Chatzarakis, F. Di Trapani, M.G. Douvika, K. Roinos, N.M. Vaxevanidis, P.G. Asteris, Adv. Materials Res. 6169 (2017)

13. P.G. Asteris, A.K. Tsaris, L. Cavaleri, C. Repapis, A. Papalou, F. Di Trapani, D.F. Karypidis, Comp. Intel. Neurosc. 2016 Art. No 5104907 (2016)

14. P.G. Asteris, V. Plevris, Neural Comput. Appl. 282207 (2017)

15. V. Plevris, P.G. Asteris, Constr. Build Mater. 55447 (2014) 